\title{
Study of tissue inhomogeneity effects on central axis radiation beam parameters using monte Carlo methods
}

\author{
Santhosh VS. ${ }^{1 *}$, Anand RK. ${ }^{2}$ \\ DOI: https://doi.org/10.17511/ijmrr.2020.i05.03
}

1* Santhosh VS, Assistant Professor, Department of Radiation Physics, Government Medical College, Thiruvananthapuram, Kerala, India.

2 Anand RK, Assistant Professor, Department of Radiation Physics, Government Medical College, Thiruvananthapuram, Kerala, India.

Introduction: The central axis radiation beam parameters are used for the dose calculations in radiotherapy and usually measured in a homogeneous medium. Human body is not homogeneous in nature and the incident beam has to travel through different medium such as bone tissue air etc to reach the tumor. Objective: The objective of the present work is to study the effects of tissue Inhomogeneity on central axis beam parameter such as percentage Depth Dose using Monte Carlo Methods Materials and Methods: The Monte Carlo simulation is a virtual experiment and can be conducted with the Monte Carlo software tool installed in a PC. Input files are written as per the specification of the Monte Carlo code. Two radiation beams beans commonly used for radiation treatment such as Cobalt 60 and $6 \mathrm{MV} \mathrm{X}$ ray were used for the simulation. Results: Depth Dose characteristics in homogeneous tissue medium for Cobalt60 and $6 \mathrm{MV} X$ rays beams were studied and is consistent with the published experimental values.In the second case, at the interface between tissue and bone the PDD pattern changed as reported by the previous works. And the absorbed dose at bone layer is higher than the dose value predicated in a homogeneous condition. In the next simulation we conducted the simulation for a tissue air tissue medium. Conclusion: The present study clearly demonstrate that Monte Carlo methods simulation can be used as a tool for estimation of dose in tissue Inhomogeneity where measurements are seldom possible.

Keywords: Tissue inhomogeneity, Monte Carlo methods, Percentage Depth Dose, Radiotherapy

Corresponding Author

Santhosh VS, Assistant Professor, Department of Radiation Physics, Government Medical College, Thiruvananthapuram, Kerala, India.

Email: vssanthosh30@gmail.com

\section{How to Cite this Article}

To Browse

Santhosh VS, Anand RK. Study of tissue inhomogeneity effects on central axis radiation beam parameters using monte Carlo methods. Int J Med Res Rev. 2020;8(5):352-362.

Available From

https://ijmrr.medresearch.in/index.php/ijmrr/article/ view/1212

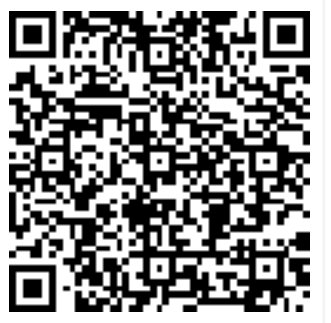




\section{Introduction}

The outcome of radiotherapy in cancer care is heavily dependent on the accuracy of radiation dose delivered to the tumor [1]. In radiotherapy collimated beams of radiation first incident on the patient surface and then transported through the body to reach the tumour.

During this transport energy is deposited. The aim of quality radiotherapy is to give maximum energy deposition (dose) to tumour and minimum dose to surrounding normal tissues. To achieve this aim careful treatment planning process and accurate treatment planning systems requiredhe radiation treatment planning process includes the derivation of patient anatomical information.

This information is then used to determine the location of tumor and important normal tissue that could be affected by radiation treatment. Different types of dose calculation algorithm are used in modern Treatment Planning Systems. Conventional TPS calculation models were based on a simple tabular representation of the dose distribution that was obtained directly from beam measurements.

Standard isotope tables and charts are then prepared based on these measurements. These tables are used by TPS for patient dose calculations. Table based TPS required a lot of measured data tables. Measurements are usually taken in homogeneous water or water equivalent phantoms and the measured values are used to calculate the dose in human body.

The evaluation of the accuracy of these dose calculation algorithms are usually be carried with experimental measurements in a homogeneous media like water or water equivalent phantoms [2] [3]. However in actual clinical practice the radiation beam has to transport through a human body and human body is not a uniform media comparing with the standard experimental media like water phantoms.

The human body consists of a variety of tissues and cavities with different physical and radiological properties. Most important among these, from a radiation dosimetry perspective, are tissues and cavities that are radiologically different from water, including lungs, oral cavities, teeth, nasal passages, sinuses and bones. In some instances, foreign materials, such as metallic prostheses, are also present.
The dose calculation algorithms commonly used for treatment planning based on measured data were not able to exactly predict the characteristics of dose distributions under the perturbation of Inhomogeneity since the measurements are carried out in a homogeneous water phantom [4] [5]. To maximize the therapeutic benefit of radiation therapy, it is essential that the absorbed dose delivered to all irradiated tissues in the presence of such inhomogeneities be predicted accurately [6] [7] [8] [9] [10].

The Monte Carlo method which is a mathematical tool based on probabilistic model of objectenvironment or object-object(s) interactions gives a numerical solution to a problem based on random statistical trials are used to solve various problems in radiation transport. The Monte Carlo methods can also be used to solve various problems associate with radiotherapy. Through this method many quantities of interest associated with radiation treatment planning and dosimetry can be predicted [11] [12] [13]. It was reported by many authors that Monte Carlo based calculations are best suited for the dose calculation predication where measurements are seldom possible in radiotherapy and can be used as a bench marking tool in predicting dose distributions in phantoms, especially in cases where the experimental dose measurement is very difficult, or reaches its limitations [14] [15] [16] [17]. Monte Carlo method can be used as a bridge between measurements and analytically based numerical calculations [18] [19] [20]. It has been reported that dose measurements at the interface between two media are common dosimetry problem and Monte Carlo methods can be effectively implemented to calculate dose in this situations[21] [22].Many authors investigated the perturbation effects in the presence of in-homogeneity and they concluded that Monte Carlo methods are efficient tool for predicating dose [23] 2 [24] [25]. However the implementation of Monte Carlo methods for routine clinical practice and dosimetry requires more and more studies and results. The objective of the present work is to study the effects of tissue Inhomogeneity on central axis beam parameter such as percentage Depth Dose using Monte Carlo Methods.

\section{Material and Methods}

Study Setting: Department of Radiotherapy, Government Medical College, Thiruvananthapuram.

Type of Study: Monte Carlo simulation studies. 
Sampling Method: This is a simulation study and the dose values at the point of interest were given by the Monte Carlo output files and these dose values used to generate the Percentage Depth Dose curves,

Study duration: December 2015 to March 2020

Ethical consideration and Permission: No ethical consideration required and Permission obtained

Study tools: The Monte Carlo simulation is a virtual experiment using Monte Carlo software tool (code) installed in a PC.The code models the propagation of photons, and electrons with kinetic energies between $1 \mathrm{keV}$ and $10 \mathrm{GeV}$. Virtual phantoms with and without Inhomogeneity are modeled using the Monte Carlo input files. The input files consist of common blocks and are written as per the specification of the Monte Carlo code.

The input parameters are particle source, geometry in which the particles are being transported, Cross sections, interaction and transport methods of the particles being simulated and for scoring (accumulating) the results for the quantities of interest. The Monte Carlo output is in the form of dose per fluence and were converted to percentage depth dose values using the equation

Study design: Monte Carlo simulation is a virtual experiment in which the radiation beam incident and transported through the medium. Here the details of the experimental condition as per the requirements to be specified

Geometry Specification; Most important specification for any Monte Carlo simulation is the geometry specification. In our study the medium of transport is a block of tissue with and without Inhomogeneity and was modeled as a block of tissue with cross section area $30^{\prime} 30 \mathrm{~cm} 2$ and a thickness of $30 \mathrm{~cm}$. The region for dose estimation or dose scoring was modeled as a cylinder of radius $0.2 \mathrm{~cm}$ at the central axis.

This region was divided into small layers of thickness $0.05 \mathrm{~cm}$ thickness. This small cylinders are our region of interests and total energy fluence in these regions were recorded. The simulation was conducted for three situations to study the effects of Inhomogeneity and described as follows

01. In the first situation the radiation beam is incident on a Homogeneous medium of human tissue as shown in the figure.

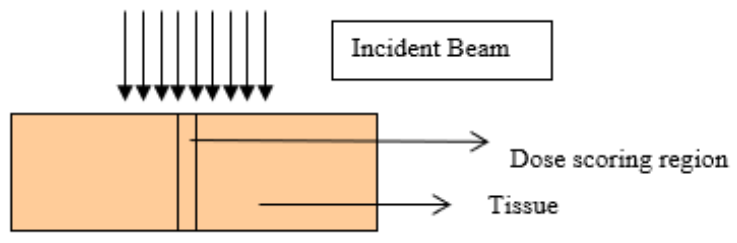

03. In the second case the beam is incident on a Heterogeneous medium of tissue and bone. First layer is tissue followed by a layer of Bone. Third layer is again tissue.

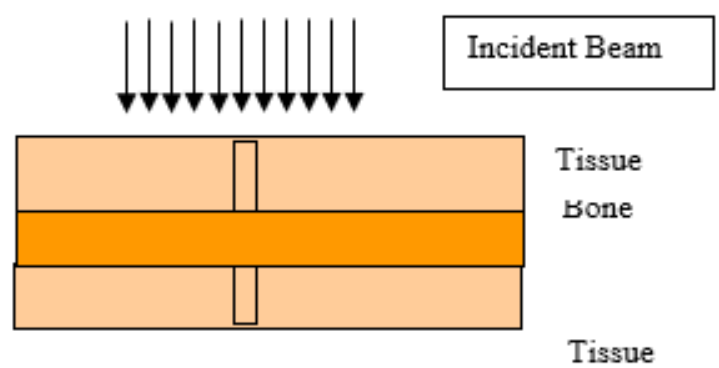

02. In the third case the beam is incident on a Heterogeneous medium of tissue and air. First layer is tissue followed by a layer of air. Third layer is again tissue. Such geometries are usually seen in the lung.
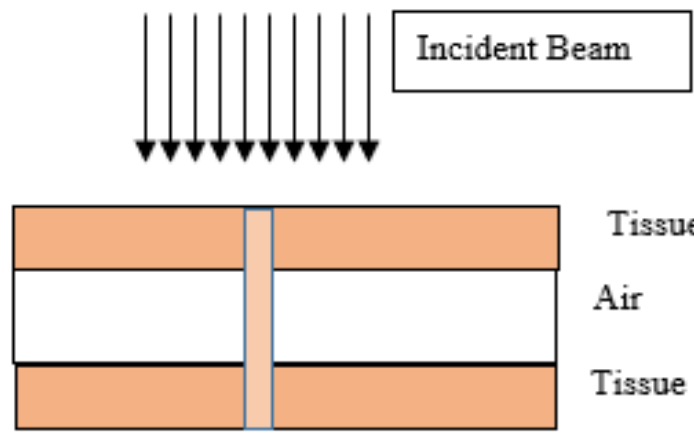

Tissue

Air

Tissue

\section{Fig: 1. Geometry specifications}

Source Specifications: The next input parameter to be specified is details of radiation beam that need to be transported. The incident beam was modeled as a surface source located directly in front and normal to the front face of the medium.

The study was conducted for two prominent photon beams commonly used for treatment such as cobalt 60 beam and 6 MV X-rays from a linear accelerator. The details of incident energy spectrum required for simulation were taken from the published values by Mohan et al [16]. 
Material Specifications: For the Monte Carlo simulation the details of materials involved in the transport media needs to be specified. Three materials are involved in our simulations.

They are adult tissue, Bone and air. The required details are composition and mass density of materials utilized in the present work are listed in Table.

\begin{tabular}{|l|l|c|}
\hline Material & $\begin{array}{l}\text { Density } \\
(\mathrm{gm} / \mathrm{cc})\end{array}$ & Composition and Mass fraction \\
\hline \multirow{3}{*}{ Soft } & 1 & $\mathrm{H}(0.101)$ \\
tissue & & $\mathrm{C}(0.111)$ \\
& & $\mathrm{N}(0.26)$ \\
Bone & \multirow{3}{*}{1.41} & $\mathrm{O}(0.762)$ \\
& & $\mathrm{H}(0.064)$ \\
& & $\mathrm{C}(0.263)$ \\
& & $\mathrm{N}(0.039)$ \\
& & $\mathrm{O}(0.436)$ \\
\hline \multirow{3}{*}{ Air } & \multirow{3}{*}{0.001293} & $\mathrm{Na}(0.001)$ \\
& & $\mathrm{Cl}(0.001)$ \\
& & $\mathrm{Mg}(0.001)$ \\
& & $\mathrm{P}(0.06)$ \\
& & $\mathrm{S}(0.03)$ \\
& & $\mathrm{K}(0.001)$ \\
& & $\mathrm{C}(0.00014)$ \\
& & $\mathrm{N}(0.75519)$ \\
& & $\mathrm{O}(0.23179)$ \\
& $\mathrm{Ar}(0.01288)$ \\
\hline
\end{tabular}

\section{Material Specifications used in the work}

Total energy deposited in the small cylindrical regions was determined using an energy deposition tally available in the Monte Carlo code.

PDD values are then calculated dividing the energy deposited in each cell by the value of maximum energy deposition. Number of particles transported in this modeling were 107.

\section{Results}

01. The percent depth Dose(PDD ) curves in homogeneous tissue medium for 60Co and 6MV $x$ rays were given in figure $2(a)$ and (b). For both beams the dose increases at first and reaches a maximum and then decreases as the depth increases.

The maximum dose is at $0.425 \mathrm{~cm}$ depth for $60 \mathrm{Co}$ beams. For 6MV photons the PDD curves are given in figure 2(b). Depth of maximum dose obtained is $1.5 \mathrm{~cm}$.

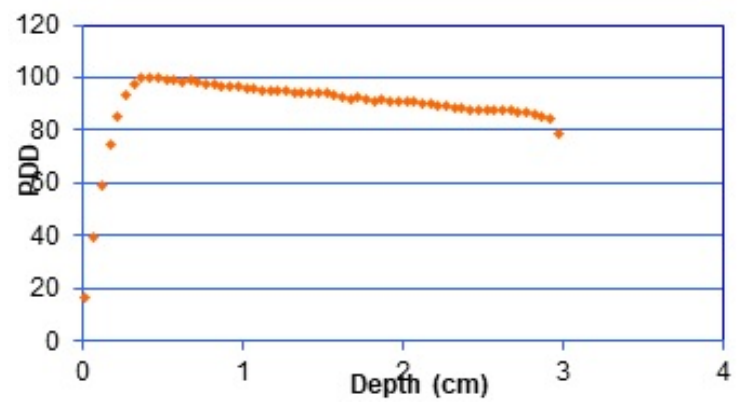

Figure 2 (a)PDD curves for 60Co Beams in a homogeneous tissue medium

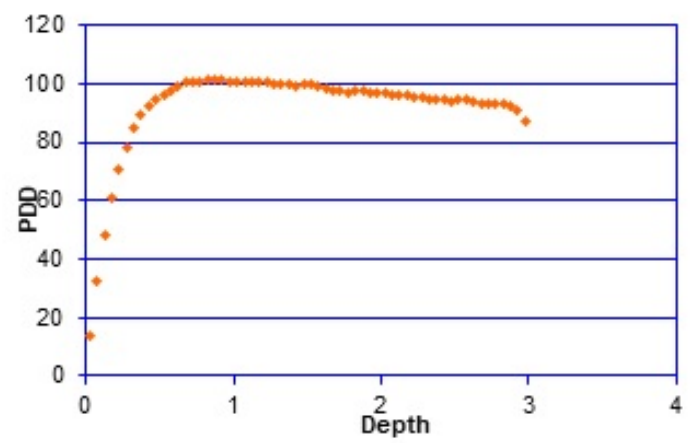

Figure 2 (b) PDD curves for 6MV Beams in a homogeneous tissue medium

2. Combination of tissue- Bone- Tissue medium: The Percentage depth dose curves obtained in the second set of simulation is given in figure 3 (a) and (b) for $60 \mathrm{Co}$ and $6 \mathrm{MV} x$ ray beams are shown in figure 3(a) and 3(b).

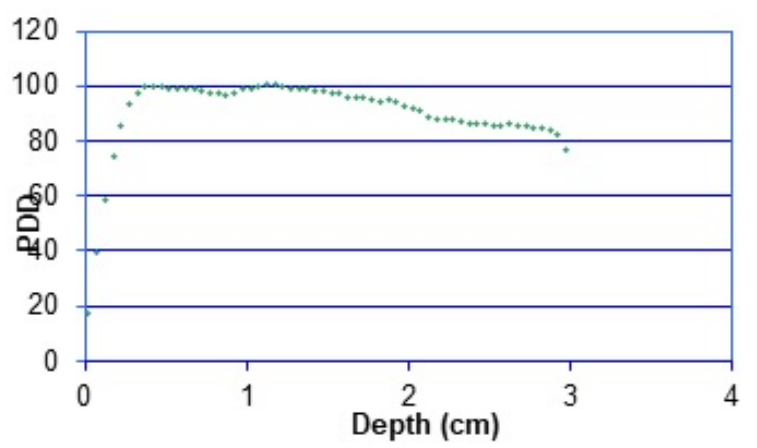

Figure 3 (a) PDD curves for 60Co Beams in tissue -Bone -Tissue medium

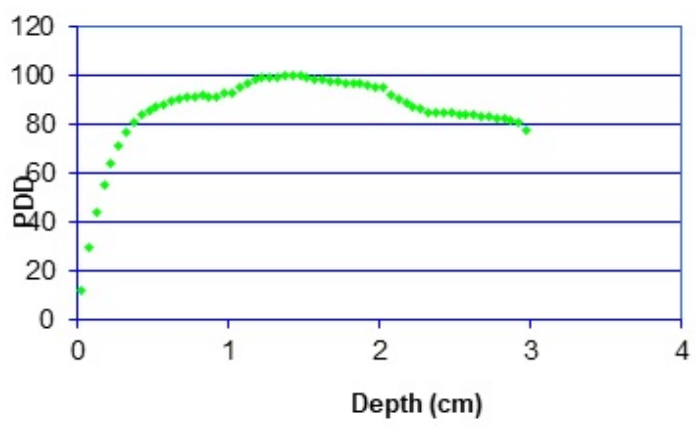


Figure 3(b) PDD curves for 6MVLinac Beams in tissue -Bone -Tissue medium

The PDD values in both homogeneous and TissueBone-Tissue situations for $60 \mathrm{Co}$ case are are shown in table 2. Same trend is also observed for 6MV Linac beam.

\begin{tabular}{|l|l|l|}
\hline Depth & \multicolumn{1}{|c|}{ Homogeneous tissue } & \multicolumn{1}{c|}{ Tissue-Bone-Tissue } \\
\hline 0.025 & 17.0 & 17.0 \\
\hline 0.125 & 58.8 & 58.8 \\
\hline 0.325 & 97.8 & 97.8 \\
\hline 0.375 & 99.9 & 99.9 \\
\hline 0.425 & 100.0 & 100.0 \\
\hline 0.475 & 99.6 & 99.6 \\
\hline 0.525 & 99.0 & 99.0 \\
\hline 0.975 & 96.8 & 98.9 \\
\hline 1.075 & 96.0 & 100.0 \\
\hline 1.175 & 95.2 & 100.3 \\
\hline 1.775 & 91.9 & 95.2 \\
\hline 1.975 & 91.0 & 92.4 \\
\hline 2.025 & 90.7 & 92.2 \\
\hline 2.075 & 90.9 & 90.8 \\
\hline 2.125 & 90.3 & 88.8 \\
\hline 2.775 & 87.0 & 85.1 \\
\hline 2.875 & 85.5 & 83.7 \\
\hline 2.925 & 84.4 & 82.6 \\
\hline 2.975 & 78.6 & 76.9 \\
\hline & & \\
\hline
\end{tabular}

Table:- 2 PDD values for Cobalt 60 beams in homogeneous and Tissue bone tissue mediums

3. Combination of Tissue -Air-Tissue medium: The PDD curves for the tissue -air- tissue medium for cobalt 60 beam is shown in figure 3 and the comparison of PDD values with homogeneous tissue is case is given in table 3

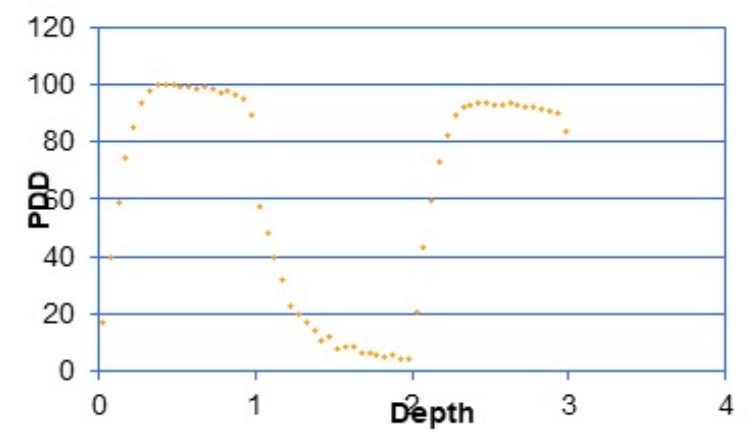

Figure.3 PDD curves for Cobalt 60 Beams in tissue -air -Tissue medium

\begin{tabular}{|l|l|l|l|}
\hline Depth & Homogeneous & Tissue-Air-Tissue & \% Deviation \\
\hline 0.025 & 17.0 & 17.0 & 0.0 \\
\hline 0.475 & 99.6 & 99.6 & 0.0 \\
\hline
\end{tabular}

\begin{tabular}{|l|l|l|l|}
\hline 0.925 & 96.6 & 95.3 & 1.3 \\
\hline 0.975 & 96.8 & 89.1 & 7.9 \\
\hline 1.025 & 96.3 & 57.1 & 40.7 \\
\hline 1.125 & 95.4 & 39.6 & 58.5 \\
\hline 1.325 & 94.6 & 17.0 & 82.1 \\
\hline 1.775 & 91.9 & 5.7 & 93.8 \\
\hline 2.025 & 90.7 & 20.6 & 77.3 \\
\hline 2.075 & 90.9 & 42.9 & 52.8 \\
\hline 2.275 & 89.8 & 89.2 & 0.6 \\
\hline 2.525 & 87.7 & 93.0 & -6.0 \\
\hline 2.575 & 87.6 & 93.0 & -6.2 \\
\hline 2.975 & 78.6 & 83.5 & -6.3 \\
\hline
\end{tabular}

Table; PDD values for Cobalt 60 beams in homogeneous and Tissue bone tissue mediums

\section{Discussion}

One of the most important tasks in radiotherapy is the determination of accurate dose distributions within the patients. This dose distributions are usually generated using algorithms whose accuracy depends on the accuracy of measured parameters Incorporated in the TPS and its analytical capability. The measured values has limitations in the presence of Inhomogeneity and in such situation Monte Carlo simulation can be used to evaluate the accuracy.

Monte Carlo simulation can be termed as a virtual experiment in which the clinical situations can be modeled.Many authors Investigated the use of Monte Carlo methods in various radiotherapy applications[26] [27] [28] [29] [30] [31] [32] [33]. The objective of the present study also focus on the use of Monte Carlo Method in radiotherapy application.

In the present study we use Monte Carlo method to find out the PDD values and PDD curves for two radiation beams such as Cobalt 60 gamma radiation and $6 \mathrm{MV} x$ rays from a linear accelerator which are commonly used for cancer treatment by transporting them through a homogeneous tissue medium and two heterogeneous medium. First the PDD curves in the homogeneous medium generated for which accurate experimental measurements are possible. The dose build up properties is as expected, reaches a maximum and then decreases. The Depth of Maximum dose ( $d$ max) values which is an important parameter for the dosimetry. The dmax values obtained in our simulations is 0.425 for cobalt beam and and 1.5 for $6 \mathrm{MV} \times$ rays is $1.5 \mathrm{~cm}$. Our results are well contestant with the standard values published in British journal of Radiology [34]. 
Mohan et al reported the energy and angular distributions of linac beams by Monte Carlo simulations [35]. Teimouri et al studied the dosimetry parameters of cobalt 60 beams and reported that their values are within $1 \%$ percent comparing with the published data of British Journal of Radiology [36]. Mora et al simulated a Telecobalt machine using Monte Carlo methods and the depth dose parameters were obtained for the simulated beam in a water phantom [37].

In the second part of simulation we conducted the Monte Carlo simulation for a modicum with tissue at first layer and then bone and then again tissue. Our results shows that in the first layer of tissue the PDD pattern is exactly same as that of homogeneous situation as mentioned above. However at the interface between tissue and bone the PDD pattern changed. The absorbed dose at bone layer is higher than the dose value predicated in a homogeneous condition. The deviation of up to 5.4 percentage was observed in the bone layer.

The theoretical reason for this change in dose distribution is due to change in material composition and consecutive change in absorption of radiation beam and change in primary radiation beam flounce, secondary electron flounce as well as scattered radiation flounce. The photon attenuation at bone is more predominant due to high electron density. More over at the interface between the two media the reason for dose distribution is due to loss of electron equilibrium conditions [38]. Surendra N Rustigi et al used Monte Carlo methods to investigate the perturbation effects caused by high density Inhomogeneity for small field sizes and found good agreement between experimental and Monte Carlo simulations in dose reduction factors [39]. Cardosa et al studied the perturbation effects at the tissue bone interface and they observe that bone has a large effect on the central axis dose of small photon beams. The dose to the bone is increased while the dose beyond the bone is decreased.

They concluded that If the bony heterogeneity is not taken into account, differences of 7 and $4 \%$ can be found in PDD planning to $2 \times 2$ and $10 \times 10 \mathrm{~cm} 2$ field sizes, respectively, at soft tissue after this heterogeneity [40]. Nisbet et al reported that certain commonly used algorithms like collapsed cone and pencil beam models do not predict the interface zone well. In front of the bone substitute, both models underestimate the dose and beyond the bone, both models overestimate the dose [41].
The present study also indicates that Monte Carlo methods are capable of predicting the dose variations in tissues with density variation and Inhomogeneity. In the next simulation we conducted the simulation for a tissue air tissue medium. Such geometries are observed while treating with lung cavities and other anatomical regions where air cavities are present. In our study the first layer of tissue the dose distribution is exactly as in the earlier.

However as the beam passes through the tissue air interface the distribution changes drastically. The dose deposition in air become very small. At the first tissue air interface the deviation from homogeneous condition is up to $7 \%$.

PDD values at other points in the air medium show variation up to $95.3 \%$ than the homogeneous condition. This much variation due to the fact that absorbed dose in air will be much less than that in tissue due to the difference in their densities and change in electronic equilibrium conditions [38].

Interestingly it is also observed that a buildup condition occur at the second air tissue interface. In this region the PDD values are only $20.6 \%$ to $42.09 \%$ at the first few Millimeters and increases up to $93.5 \%$ of $\mathrm{D}$ max values as specified for the homogeneous conditions.

Antonella Fogliatal et al extensively studied the dose calculation algorithms calculated PDD curve in the presence of Inhomogeneity. They compare the performances of several dose calculation algorithms and confirmed the inadequacy of certain algorithms to manage dose calculation inside heterogeneous media, especially for small fields in low density media such as air.

They concluded that while implementing algorithms in clinical practice the accuracy evaluation should be carried out [42]. Bayatiani et al examined the impact of air cavities of sinuses on radiotherapy dose distribution using Monte Carlo methods and they concluded that the presence of air cavities leads to the generation of overdose and under-dose regions in the intersection of air-tissue and it also is a contributing factor in Inhomogeneity and fluctuation in dose distribution.

The larger the cavity size is the more discontinuity and also fluctuations in the distribution of dose can be seen. Changes in dose distribution and dose fluctuation in the air cavity edges are quite evident [43]. 
Behrens et al studied the build-up effects behind air cavities using Monte Carlo (MC) simulations and concluded that build up effects should be taken into consideration when choosing the accelerator energies with the increasing use of IMRT and radiosurgery and small fields [44]. It was also reported that in many clinical situation the air cavities present in such as those found in upper respiratory passages.

This air cavities results the under dosing of lesions distal to air cavities and occurs due to the loss in lateral charged-particle equilibrium (CPE) especially for smaller field sizes, resulting in more frequent recurrence of the cancer treated. It was also reported that In addition to the loss of lateral charged particle equilibrium the

Presence of higher photon energy after the air cavity results second build up resulting undesirable distributions [45]. Our studies clearly demonstrate the perturbation effects caused by the presence of Inhomogeneity while a radiation beam is transporting through the human tissues. The Monte Carlo study can also be used to estimate the Inhomogeneity correction factors that have to be incorporated for dose calculations in actual clinical situations.

The importance of dose calculation accuracy has been investigated by many authors The goal of radiotherapy is to eradicate a tumor without causing severe damage to healthy tissues An overall precision of $5 \%$ on the absorbed doses at any point in the patient is required to meet this goal. It is well established that both tumor control probabilities (TCP) and normal tissue complication probabilities (NTCP) have a sigmoid dependence on radiation dose [46].

Many studies reported that TPS even with advanced algorithms do not provide accurate dosimetry in the build up region and other inhomogenities and suggested that more advanced algorithms or sophisticated algorithms or Monte Carlo should be used for accurate tailoring of dose in head and neck tumors [25] [28] [46]. The interface effects in the presence of Inhomogeneity are a common dosimetry problem encountered in routine treatment planning process [47] [48].

Treatment planning systems express dose distributions in terms of so-called isodose lines connecting points of equal dose, and superimposed on CT sections through the patient under study.
For an extremely heterogeneous anatomy algorithm widely employed in commercial radiotherapy treatment planning systems show a smooth isodose distribution. However true dose distributions of such a narrow photon beam in heterogeneous terrain will be grossly distorted [49][50]. Introduction of Monte-Carlo simulation into the patient dose calculation systems will solve such problems and provide more accurate dose distributions. The present work clearly shows that Monte Carlo methods can predict the dose perturbations due to tissue inhomogeineities. We believe that our work is a stepping-stone for the development of a Monte Carlo based Dose computation system to improve the clinical outcome of radiotherapy.

\section{Limitation}

The present study analyses the use of Monte Carlo methods to calculate dose at central axis only. The study confined to Inhomogeneity regions such as bone tissue interfaces, air gaps.The study does not address the other dose uncertainty regions such as beam edges etc. The study is carried out with simple geometries. A study with a real clinical geometries is not carried out. More complicated patient cross section based on CT anatomy not undertaken in the study. Future works considering these aspects may be undertaken.

\section{What this study adds to existing knowledge}

Before the commencement of radiation treatment the radiation oncology team desires to deliver accurate radiation dose to the tumor and minimum dose to normal tissues. The dose is estimated using experiments and treatment planning system. The present study provides an understanding about the strength and limitations of the dose calculation systems used to the radiation oncology team. The study reveals the need for quality assurance protocol for the treatment planning systems used for cancer treatment. Monte Carlo Methods can be used successfully to study the dose calculation in the presence of Inhomogeneity.

\section{Conclusion}

The present study clearly demonstrate that lowdensity materials such as air cavities as in lung tissue etc or high density mediums such as bone in the path of the radiation beam will alter the dose distribution in the tumor. 
For the accurate delivery of the radiation dose to the tumor, the dose perturbation caused by these inhomogeneity has to be taken care. Monte Carlo simulation is found to be an accurate method to evaluate the in homogeneity effects.

\section{Author's Contribution}

Dr. Santhosh VS was the primary investigator of the study, collected data, Drafting the manuscript. Dr. Anand RK helped to get data related to tissues and manuscript preparation.

\section{Reference}

01. Radiation dose in Rradiotherapy from prescription to Delivery. International Atomic Energy Agency. IAEA-TECDOC-896. 1996.

[Crossref]

02. Tissue Inhomogeneity Corrections for Megavoltage Photon Beams. Task group No 85, American Association of Physicists in MedicineMedical Physics Publishing. 2004, Report No-85. [Crossref]

03. Faiz M Khan, Roger A Potish, editors. Treatment planning in Radiation Oncology. 1st ed Williams \& Wilkins. 1998.

[Crossref]

04. Ahnesjo A, Aspradakis MM. Dose calculations for external photon beams in Radiotherapy. Phys Med Biol. 1999; 44;99-155.

doi:10.1088/0031-9155/44/11/201 [Crossref]

05. Niko Papanikolaou, Sotirios Stathakis. Dosecalculation Algorithms in the Context of Inhomogeneity Corrections for High Energy Photon Beams. Med Phys. 2009; 36(10)476575.

doi: $10.1118 / 1.3213523$ [Crossref]

06. Andreo P, Burns DT, Nahum AE, Seuntjens J \& Attix $\mathrm{F} \mathrm{H}$. Fundamentals of ionizing Radiation Dosimetry. John Wiley \& Sons. 2017. [Crossref]

07. Pedro Andreo. Dose to 'Water-Like' Media or Dose to Tissue in MV Photons Radiotherapy Treatment Planning- Still a Matter of Debate. Phys Med Biol. 2015;60(1)309-37.

doi: 10.1088/0031-9155/60/1/309 [Crossref]
08. Sonja Dieterich, Eric Ford, Dan Pavord, Jng Zeng. Practical Radiation Oncology Physics, A Companion to Gunderson \& Tepper's Clinical Radiation Oncology- Chapter 5. Elsevier Health Sciences. 61-86;2015.

[Crossref]

09. A Dutreix. "When and how can we improve precision in radiotherapy?". Radiother Oncol. $1984 ; 2 ; 275-292$.

doi: $10.1016 / s 0167-8140(84) 80070-5$ [Crossref]

10. S Dische, MI Saunders, C Williams, A Hopkins, and $E$ Aird. Precision in reporting the dose given in a course of radiotherapy. Radiother Oncol. $1993 ; 29 ; 287-93$. doi:10.1016/0167-8140(93)90146-y [Crossref]

11. J F Williamson. Radiation Transport Calculations in Treatment Planning. Comput Med Imaging Graph. May-Jun 1989;13(3)251-68.

DOI: $\quad 10.1016 / 0895-6111(89) 90132-8$ [Crossref]

12. Joao Seco, Frank Verhaegen, editors. Monte Car -lo Techniques in Radiation Therapy. CRC Press. Available at: [Article] [Crossref]

13. Bielajew AF. Fundamentals of the Monte Carlo method for neutral and charged particle transport. The University of Michigan. 2001. Available at: [Article] [Crossref]

14. Andreo P. Monte Carlo techniques in Medical Rad -ation Physics. Phy Med Bio. 1991;36;861-920. doi: 10.1088/0031-9155/36/7/001 [Crossref]

15. Fix MK, Keall PJ, Dawson K, Siebers JV. Monte Carlo source model for photon beam radiotherapy- Photon source characteristics. Med Phys. 2004 Nov;31(11)3106-21. doi: $10.1118 / 1.1803431$ [Crossref]

16. Pedro Andreo Monte. Carlo Simulations in Radiot herapy Dosimetry. Rad Onc. 2018;6;27;13;121. doi:1186/s13014-018-1065-3 [Crossref]

17. Verhaegen F, and Seuntjens J. Monte Carlo modelling of external radiotherapy photon beams. Phys Med Biol. 2003;48;pp-R107-R164. doi: $10.1088 / 0031-9155 / 48 / 21 /$ r01 [Crossref] 
18. Mackie TR. Applications of the Monte Carlo method in radiotherapy, in- Kase KR, Bjarngard $\mathrm{BE}$, Attix FH, Dosimetry of Ionizing Radiation. Academic Press, Inc, San Diego. Vol-III,1990: 541-620.

[Crossref]

19. Ding GX. Dose discrepancies between Monte Carlo calculations and measurements in the buildup region for a high-energy photon beam. Med Phys. 2002;Nov;29(11)2459-63. doi: 10.1118/1.1514237 [Crossref]

20. Brualla L, Rodriguez M, Lallena AM. Monte Carlo systems used for treatment planning and dose verification. Strahlenther Onkol. 2017;Apr;193(4)243-259.

doi: $\quad 10.1007 / \mathrm{s} 00066-016-1075-8 \quad$ [Crossref]

21. Mohan R, and Antolak J. Monte Carlo techniques should replace analytical methods for estimating dose Distributions in radiotherapy treatment planning. Med Phys. 2001;28;pp-123-126. [Crossref]

22. Mauceri T, Kenneth Kase. Effects of ionization ch amber construction on dose measurements in a Heterogeneity. Med Phys. 1987;7-8;14(4)653-6. doi: 10.1118/1.596034 [Crossref]

23. Fujio Araki. Monte Carlo-based correction factors for ion chamber dosimetry in heterogeneous phantoms for megavoltage photon beams. Physics in Medicine and Biology. 2012;57( 22)7615-7627.

doi: $10.1088 / 0031-9155 / 57 / 22 / 7615$ [Crossref]

24. Antonella Fogliata, Eugenio Vanetti, Dirk Albers, Carsten Brink, Alessandro Clivio, T Knoos, G Nicolini Luca Cozzi. On the Dosimetric Behaviour of Photon Dose Calculation Algorithms in the Presence of Simple Geometric HeterogeneitiesComparison with Monte Carlo Calculations. Phys Med Biol. 2007; Mar-7;52(5)1363-85.

doi: 10.1088/0031-9155/52/5/011 [Crossref]

25. Al Hallaq HA, Reft CS, and Roeske JC. The dosimetric effects of tissue heterogeneities in intensity-modulated radiation therapy (IMRT) of the head and neck. Phys Med Biol. 2006 Mar7;51(5)1145-56.

doi: 10.1088/0031-9155/51/5/007 [Crossref]
26. A Toutaoui, S Ait chikh, N Khelassi-Toutaoui and B Hattali. Monte Carlo photon beam modeling and Commissioning for radiotherapy dose calculation algorithm. Physica Medica. 201430(7)833-837, PMID: 24947967.

[Crossref]

27. Mohammad Taghi, Bahreyni Toossi, Bagher Farhood, Shokouhozaman Soleymanifarda. Evaluation of Dose Calculations Accuracy of a Commercial Treatment Planning System for the Head and Neck Region in Radiotherapy. Rep Pract Oncol Radiother. 2017;22(5)420-427. doi: 10.1016/j.rpor.2017.06.001 [Crossref]

28. Mahmoudi G, Farhood B, Shokrani $P$, Amouheidari A, Atarod $M$. Evaluation of the photon dose calculation accuracy in radiation therapy of malignant plural mesothelioma. J Cancer Res Ther. 2017.

Available from: doi: 10.4103/0973-1482.187284 [Article] [Crossref]

29. Yuichi Akino, Indra J Das, Gregory K Bartlett, Hualin Zhang, Elizabeth Thompson, Jennifer E Zook. Evaluation of Superficial Dosimetry Between Treatment Planning System and Measurement for Several Breast Cancer Treatment Techniques. Med Phys. 2013;Jan;40(1)011714. doi: $10.1118 / 1.4770285$ [Crossref]

30. Niroomand Rad A, Harter KW, Thobejane S, and Bertrand $\mathrm{K}$. Air cavity effects on the radiation dose to the larynx using Co-60, 6 MV and $10 \mathrm{MV}$ photon beams. Int J Radiat Oncol Bio. 1994;Jul$30 ; 29(5) 1139-46$.

doi: 10.1016/0360-3016(94)90411-1 [Crossref]

31. Chow JC, Jiang R, Leung MK. Dosimetry of oblique tangential photon beams calculated by uperposition/convolution algorithms- a Monte Carlo evaluation. J Appl Clin Med Phys. $2010 ; 12(1) 3424$.

doi: $10.1120 / j a c m p . v 12 i 1.3424$ [Crossref]

32. Elcim Y, Dirican B, Yavas O. Dosimetric comparison of pencil beam and Monte Carlo algorithms in conformal lung radiotherapy. $j$ Appl Clin Med Phys. 2018;19(5)616-624.

doi: $10.1002 / a c m 2.12426$ [Crossref] 
33. Demarco JJ, Chetty IJ, Solberg TD. A Monte Carlo tutorial and the application for radiotherapy treatment planning. Med Dosim. 2002;27(1)43-50.

doi: $10.1016 / \mathrm{s} 0958-3947(02) 00087-0$ [Crossref]

34. Central Axis Depth. Dose Data for Use in Radiotherapy. British Journal of Radiology, BJR. Suppl, 25,1996.

[Crossref]

35. Mohan R, Chui C, Lidofsky L. Energy and angular distributions of photons from medical linear accelerators. Med Phys. 1985;12;592597.

doi: $10.1118 / 1.595680$ [Crossref]

36. F Verhaegen. Evaluation of the EGS nrc Monte Carlo Code for Interface Dosimetry Near high-Z Media Exposed to Kilovolt and 60 Co Photon. Phys Med Biol. 2002; May 21;47(10)1691-705. doi:10.1088/0031-9155/47/10/306 [Crossref]

37. B Teimouri Sichani, M Sohrabpour. Monte Carlo Dose Calculations for Radiotherapy Machines. Theratron 780-C Teletherapy. DOI: 10. 1088/0031-9155/49/5/011 [Crossref]

38. G M Mora, A Maio, D W Rogers. Monte Carlo Simulation of a Typical Co 60 Therapy Source. Med Phy. 1999;Nov;26(11)2494-502.

doi: $10.1118 / 1.598770$ [Crossref]

39. Faiz M Khan. The Physics of Radiation Therapy, 4th edn. Lippincott Williams \& Wilkins. 2012.

[Crossref]

40. S N Rustgi, A K Rustgi, Steve B Jiang, K M Ayyangar. Dose perturbation caused by highdensity inhomogeneities in small beams in stereotactic radiosurgery. Phys Med Biol. 1998 Dec;43(12)3509-18.

doi: 10.1088/0031-9155/43/12/009 [Crossref]

41. Cardoso SC, Alves VGL, da Rosa LAR, Campos LT, Batista DVS, Facure A. Monte Carlo Simulation of Bony Heterogeneity Effects on Dose Profile for Small Irradiation Field in Radiotherapy. PLoS ONE. 2010;5(5)e10466. [Article] [Crossref]
42. Nisbet A, Beange I, Vollmar H S, Irvine C, Morgan $A$ and Thwaites $D$ I. Dosimetric verification of a commercial collapsed cone algorithm in simulated clinical situations. Radiother Oncol. 2004;73 79-88.

[Crossref]

43. F Seif, MR Bayatiani, S Hamidi, M Kargaran. Investigating the Effect of Air Cavities of Sinuses on the Radiotherapy Dose Distribution Using Monte Carlo Method. J Biomed Phys Eng. 2019;Feb;9(1)121-126, PMCID: PMC6409366. [Crossref]

44. Miura H, Masai N, Yamada K, Sasaki J, Oh RJ, Shiomi $\mathrm{H}$, et al. Evaluation and commissioning of commercial Monte Carlo dose algorithm for air cavity. International Journal of Medical Physics, Clinical Engineering and Radiation Oncology. 2014;3;9.

doi: 10.4236/ijmpcero.2014.31002 [Crossref]

45. Behrens CF. Dose build-up behind air cavities for Co-60, 4, 6 and 8 MV, Measurements and Monte Carlo simulations. Phys Med Biol. 2006;Nov21;51(22)5937-50 DOI: 10. 1088/0031-9155/51/22/015 [Crossref]

46. Shahid A, Naqvi X,Allen Li, Shada W, Ramahi James C, Chu Sung-Joon Ye. Reducing loss in lateral charged-particle equilibrium due to air cavities present in x-ray irradiated media by using longitudinal magnetic fields. Med Phys. 2001;Apr;28(4)603-11.

doi: $10.1118 / 1.1357816$ [Crossref]

47. Emami BJ, Lyman A, Brown L, Coia M, Goitein FW, Munzinrider B, Shank LJ Solin, and M Wesson. Tolerance of normal tissue to therapeutic irradiation. Int J Radiat Oncol Biol Phys. 21;109-122(1991).

[Crossref]

48. RJ Chetty, B Curran, J E Cygler, J J DeMarco, G Ezzell, B A Faddegon, I Kawrakow, P J Keall, H Liu, C M Charlie Ma, D W O Rogers, J Seuntjens, D S-Bagheri, J V. Siebers of the AAPM Task Group No-105; Issues Associated With Clinical Implementation of Monte Carlo-based Photon and Electron External Beam Treatment Planning. Med Phys. 2007;(12):4818-53.

doi: $10.1118 / 1.2795842$ [Crossref] 
49. Rana $S$ and Pokharel. Verification of dose calculation algorithms in a multi-layer heterogeneous phantom using films. Gulf J Oncolog. 20131(14)63-9, PMID:23996869.

Available at: [Article] [Crossref]

50. A Fogliata, EVanetti, D Albers, C Brink, A Clivio, Tommy Knoos, G Nicolini and Luca Cozzi. On the dosimetric behaviour of photon dose calculation algorithms in the presence of simple geometric heterogeneities- comparison with Monte Carlo calculations. Phys Med Biol. 2007;52(5)136385.

doi: 10.1088/0031-9155/52/5/011 [Crossref] 